\title{
A NOVA GRADUAÇÃO DA UNISINOS: compartilhando a experiência de um ato pedagógico
}

Marly Terezinha Mallmann* Sônia Isabel Dondonis Daudt**

\section{Resumo}

Neste artigo apresentamos o processo de criação de uma proposta inovadora para o ensino na graduação, desenvolvida por um grupo interdisciplinar da Universidade do Vale do Rio dos Sinos - UNISINOS. Além de apontarmos o referencial teórico-epistemológico que sustenta a referida proposta, também discutimos as implicações que as rupturas de paradigma trouxeram para o processo de ensino atualmente em andamento na Universidade. Convidamos o leitor a conhecer o processo que gerou essa forma de entender e viver a educação, bem como a acompanhar o relato da experiência vivida pelo grupo de professores que recebeu a tarefa de pensar uma nova graduação.

Descritores: diretrizes curriculares nacionais; currículos de enfermagem; educação em enfermagem

\begin{abstract}
In this article we present the process of creation of an innovative proposal for undergraduate teaching, developed by an interdisciplinary group at "Universidade do Vale do Rio dos Sinos - UNISINOS". Besides pointing out the theoretical-epistemological referential supporting this proposal, we will also be discussing the implications some paradigm ruptures have brought to the educational process presently being used at this University. We would like to introduce the reader to the process behind this way of understanding and living the educational practice, as well as to follow the account of an experience a group of teachers has had, when confronted with the task of pondering a new undergraduate program.

Descriptors: national curricular guidelines; nursing curricula; nursing education

Title: New graduate program at UNISINOS: sharing the experience of a pedagogical act
\end{abstract}

\section{Resumen}

Presentamos, con el artículo, el proceso de creación de una propuesta innovadora para la enseñanza del tercer grado, que fue desarrollada por un grupo interdisciplinar de la Universidad del Valle de Rio dos Sinos (UNISINOS). Además, apuntamos el referencial teórico-epistemológico en el que se sostiene la referida propuesta. También discutimos las implicaciones que las rupturas de paradigmas han provocado enel proceso de enseñanza que actualmente se lleva en la Universidad. Invitamos al lector a que conozca el proceso que ha generado esa forma de entender y vivir la educación, así como a acompañar el relato de la experiencia vivida por el grupo de profesores, quienes recibieron la tarea de pensar una nueva graduación.

Descriptores: directrices curriculares nacionales; currículos de enfermería: educación en enfermería

Título: La nueva graduación de UNISINOS: compartiendo la experiencia de una acción pedagógica
A elaboração de novas idéias depende da libertação das formas habituais de pensamento e de expressão. A dificuldade não está nas novas idéias, mas em escapar das velhas, que se ramificam por todos os cantos da nossa mente ${ }^{(1)}$

\section{Introdução}

Iniciamos o texto com esta epígrafe por acreditarmos que poucas passagens nos remeteriam, com tanta clareza, ao sentido que pretendemos dar a esse texto ${ }^{(1)}$.

Este é um relato que falará de mudanças e todos sabemos o quanto elas são difíceis, especialmente, se vierem, de alguma forma, ameaçar estruturas em vigor.

Quando se trata de mudar em educação, embora possa parecer um paradoxo, a situação tende a se complicar ainda mais, sendo, em geral, o mais simples anúncio - ou indício da sua necessidade -, recebido com olhares desconfiados.

Mudar em educação implica, necessariamente, mudar paradigmas, fazer rupturas com práticas e crenças tão profundamente internalizadas que chegamos, às vezes, a perder a capacidade de sair da nossa comodidade, olhar o diferente e enfrentar o desafio. Isso porque os nossos paradigmas influenciam as nossas percepções e a nossa forma de agir, fazendo-nos acreditar que o que fazemos é a "única forma possível de fazer" e imobilizando-nos frente a novos desafios. Cria-se, assim, um complicador quase instransponível, quando se trata de aceitar novas idéias e torna-nos resistentes a alterações de rumo.

Passamos por uma experiência que nos desafiou durante a sua concepção e continua a nos deixar em constante expectativa, durante a sua execução, mexendo com as nossas convicções e a nossa vontade de avançar no processo. Mesmo convencido de que a mudança de paradigma urge e se impõe como saída para uma aprendizagem que implica em autoria e comprometimento, o grupo que propôs o modelo da Nova Graduação da UNISINOS sempre teve presente o desafio que se estabelecia.

O relato do vivido, que passamos a partilhar, pretende pensar a educação a partir do binômio experiência/sentido, apresentando-se, aos que nos lêem, com o significado que depreendemos de Larrosa $^{(2)}$ como um lugar de encontro ou uma relação com algo que se experimenta, que se prova e onde se é tocado; um lugar em que nos expomos, nos arriscamos, nos abrimos ao outro, com o propósito de continuar o nosso processo de formação e transformação. Optamos por um tom mais coloquial para termos e passarmos a sensação de uma conversa em que dizemos do nosso olhar sobre o processo vivenciado, que poderá incitar à reflexão, pois temos certeza de que cada experiência é singular e receberá a tradução e o significado de quem o recebe.

Convidamos o leitor a conhecer a experiência que gerou essa forma de entender e viver a educação e a nos acompanhar por alguns parágrafos, onde esperamos poder demonstrar a experiência vivida por um grupo de professores que recebeu a tarefa de pensar uma nova graduação. Essa experiência deveria trazer possibilidades de superar alguns impasses da estrutura atual da Universidade, obrigando a abertura a reestruturações

\footnotetext{
* Pedagoga, Mestre em Educação (UNISINOS), Doutoranda em Educação (UNISINOS), professora do Centro de Ciências Humanas e integrante do Núcleo de Apoio Pedagógico (UNISINOS).

** Pedagoga, Mestre em Educação (UNISINOS), Doutoranda em Informática na Educação (UFRGS), professora do Centro de Ciências Humanas e integrante do Núcleo de Apoio Pedagógico (UNISINOS).

Email dos autores: marlytm@uol e ddaudt@terra.com.br
} 
que favorecessem uma nova forma de convivência acadêmica e uma nova experiência de aprendizagem.

Aos interessados apenas no "produto final" dessa experiência, ou seja, na explicitação mais objetiva dos princípios e pressupostos básicos que compõem a Nova Graduação, é possível "pular essa parte" indo diretamente ao "ponto", embora devamos advertir que a leitura feita dessa forma poderá ficar bastante destituída de sentido sem o conhecimento da história desta construção que gerou, nos seus participantes, positivas ressignificações na vida profissional e pessoal.

\section{O desafio de inovar: delineando possibilidades}

Em 2002, a partir da designação das instâncias superiores da Universidade, formou-se uma equipe interdisciplinar que teve como compromisso pensar e propor, em três meses, os Princípios e Pressupostos para uma Nova Graduação. O adjetivo justifica-se porque o desafio implicava em traçar novos rumos para a graduação da Universidade considerando a superação da prática docente e do modelo curricular constituído, onde os cursos são estruturados linearmente em disciplinas semestrais, favorecendo a construção de um saber fragmentado e parcial.

Essa nova proposta deveria ter o foco do trabalho deslocado do acento usual no ensino para a relevância da aprendizagem. Deveria, igualmente, considerar a realidade regional, contemplar o paradigma da construção do conhecimento em rede e possuir um formato arrojado que viesse a fomentar a pesquisa a partir de conteúdos inovadores ${ }^{(3)}$.

O grupo formado por um patrocinador e um líder que integravam o Planest $/ 2002^{(4)}$, acrescentado de professores da área pedagógica, envolvia professores dos cursos de Direito, Informática, História, Administração, Educação, Letras, Comunicação e Química, indicados pelas Direções dos Centros de Ensino, Pesquisa e Extensão.

O primeiro grande desafio, muito além de responder à expectativa da Universidade de criar uma nova proposta de trabalho acadêmico, estabeleceu-se à medida que se instituiu a necessidade de administrar as diferentes concepções epistemológicas, já que cada um trazia para o grupo distintas experiências profissionais e pessoais; além disso, embora trabalhassem na mesma Instituição, a maioria das pessoas envolvidas no processo, não se conheciam.

Os encontros foram acontecendo, nunca menos do que uma vez por semana, e as características da convivência que se estabeleceu foram, pouco a pouco, superando as expectativas. O grupo desenvolveu um relacionamento profissional e pessoal baseado no diálogo e na parceria, uma especificidade que validava a nossa crença pedagógica de que a relação dialógica torna possível a criação de um novo modelo de pensamento. Maturana ${ }^{(5)}$ postula que o conhecimento e a convivência são fenômenos inseparáveis, ou seja, o conhecimento está intrinsecamente ligado às interações que se efetivam no viver e ainda que as relações humanas acontecem sempre a partir de uma base emocional que define o âmbito da convivência, e de uma aceitação mútua, sem a qual não haverá nem coincidência de desejos nem harmonia no conviver(6).

Com o decorrer do tempo, passamos efetivamente a consolidar a experiência de colocar em cheque as concepções de educação e de conhecimento gravadas em nossas memórias e em nossos costumes.

As discussões eram atravessadas por interrupções constantes para esclarecimento de alguma idéia exposta e, eventualmente, mal compreendida por algum de nós. Isso porque, por vezes, a linguagem oriunda de cada área trazia significados diferentes para as palavras, que não se "encaixavam", em um primeiro momento, na lógica dos interlocutores.

Durante todo o tempo escrevíamos e desenhávamos, em um quadro e em grandes folhas de papel, riscando e alinhavando nossas idéias. Criávamos representações gráficas que, ao se definirem, foram ajudando-nos, pouco a pouco, a (re)significar nossa compreensão. O tempo, freqüentemente, parecia-nos insuficiente para atender à necessidade que tínhamos, tanto de falar, de estudar, quanto de dar conta do trabalho, e, embora as reuniões fossem às vezes desgastantes, o sentimento de produtividade e aprendizagem estava sempre presente ao final de cada encontro.

Propor um novo modelo para a educação implica em abandonar o "velho" modelo mental e prático e essa não é uma mudança fácil, pois mudar premissas implica em um colapso de toda uma estrutura de idéias ${ }^{(7)}$. Embora pareça contraditório, a despeito do receio natural de enfrentar as implicações que um exercício como este traz, mostrava-se mais forte do que a resistência ao desafio o desejo de vencê-lo.

Dois processos estavam claramente em andamento: a realização da tarefa a nós confiada e a experiência de aprendizagem que estávamos vivenciando ao fazermos isso. E foi principalmente a consciência da experiência de viver uma aprendizagem de forma diferente, a grande inspiradora da proposta que vimos, ao final da tarefa, delineada. Cunha ${ }^{(8)}$ muito bem observou - em pesquisa sobre professores universitários - que eles, quando questionam seu trabalho, vêem-se frente à uma situação de ressignificação do trabalho que realizam, procurando redefinir sua atuação docente de modo que procuram construir um novo papel, que responda a uma nova idéia de ensinar e aprender, com contornos ainda pouco claros mas intensamente desejados ${ }^{(8)}$

A metodologia adotada pelo grupo ao desenvolver o trabalho foi-se construindo no próprio viver da experiência, ou seja, a partir das necessidades que surgiam para vencer o desafio, de modo que nossa necessidade cognitiva era a nossa bússola. O que estávamos fazendo era muito mais do que apenas cumprir uma tarefa. Estávamos realmente rompendo com as nossas próprias crenças e práticas instaladas no nosso operar docente cotidiano.

Como um exercício, pusemo-nos a pensar sobre o que tornava esta equipe de trabalho tão produtiva e esta experiência coletiva tão prazerosa, apesar da ansiedade e das dificuldades presentes que nos levaram, inclusive, a mudar de rumo várias vezes. $\mathrm{E}$, ainda, o que pode tornar diferente o sentido de uma aprendizagem em relação a outras formas de aprender?

Sabíamos, também, que uma experiência de aprendizagem como a que estávamos vivenciando não se efetiva na maioria das salas de aula. Observando as características mais visíveis do grupo identificamos que: tínhamos experiências diversas, acabávamos de nos conhecer e pensávamos de formas diferentes sobre muitas coisas. Mas não havia nisso nada de original ou extraordinário uma vez que esta realidade também se encontra nas salas de aula de todos nós, todos os dias. Percebemos, então, que a diferença não estava nos condicionantes externos, mas na forma como estávamos conduzindo a experiência no nosso viver. Uma experiência que nos ajudou a entender que o contato com a novidade nos faz experimentar certas conseqüências do nosso modo de lidar com elas e assim elas adquirem significado para nós(9).

Olhando mais atentamente para essa forma de conduzir a experiência, percebemos algumas particularidades do nosso relacionamento que nos ajudaram a identificar mais sinais que pudessem vir a responder a essas questões. Por exemplo, que a nossa convivência era permeada por alguns componentes de caráter profundamente pedagógico, articulados pelo próprio grupo. Podemos afirmar, como participantes desta equipe que: a) compartilhávamos um objetivo e uma meta comum; b) estávamos comprometidos com a tarefa e tínhamos disciplina no trabalho; c) fomos solidários; d) aprendemos a ouvir uns aos outros com interesse 
e sem imposição de idéias; e) fomos pacientes uns com os outros e tivemos um profundo respeito pelo saber e pelo não saber do outro; f) existia reconhecida competência técnica dos integrantes; g) não havia certezas absolutas, hierarquia de saberes e todo o desenrolar o processo seguiu livre de amarras de qualquer espécie; h) havia afetividade no grupo, confiança mútua e muito bom-humor. Éramos um grupo alegre. Cada componente era sempre recebido com graça e alegria de modo que nenhuma ausência jamais deixou de ser notada.

O leitor mais atento deve ter percebido que alguns termos ou seus sinônimos aparecem de forma recorrente neste texto, como por exemplo: desafio, conflito, saber, experiência, viver, conviver, dificuldade, solidariedade e satisfação. Essa insistência não é casual e tampouco fruto de uma escrita feita sem o cuidado. Propositalmente, tentamos chamar atenção ao processo de aprendizagem que vivenciamos, ao que foi a "ferramenta" para "lapidar" a proposta da Nova Graduação, que se constituía na medida em que extraímos dessa experiência a convicção de que uma aprendizagem permeada por desafios intelectuais, cooperação e solidariedade poder trazer grande benefício ao sujeito, tanto sob o ponto de vista cognitivo quanto do humano.

Esse curso e sua estrutura poderão mudar muitas vezes, pois outras formas de trabalhar virão. Entretanto, a aprendizagem individual que constituímos a partir das interações coletivas, o processo de conhecimento e de vida que tivemos neste trabalho marcará nossa vida profissional e provavelmente mudará, de forma contundente, nossa forma de ver a educação.

A razão de contarmos essa história do grupo, para além de servir como um exemplo da possibilidade de criar e inovar a partir dos desafios, seja pelo trabalho ou pela vida, está no fato de que essa experiência, em seus detalhes mais sutis, acabou por ratificar, pelo testemunho do próprio grupo, as concepções que nortearam teoricamente os princípios e pressupostos do curso.

$\mathrm{Na}$ seqüência do texto trataremos de apresentar os fundamentos da concepção epistemológica, dos princípios e pressupostos teóricos que ajudaram a estruturar e organizar a proposta de formação da Nova Graduação da UNISINOS.

\section{A Concepção Epistemológica, os Princípios e os Pressupostos Teóricos}

Após considerar as diretrizes do Planejamento Estratégico, o público-alvo, a demanda regional e as experiências similares já realizadas em outras Instituições Acadêmicas ${ }^{(12)}$, a equipe ocupou-se de delinear o curso, passando a trabalhar nas características da concepção de aprendizagem que viria a sustentar o novo formato, bem como seus princípios e pressupostos teóricos.

A Concepção Epistemológica que sustenta a Nova Graduação é interacionista, sócio-cultural, construtivista, sistêmica e transcendente ${ }^{(11)}$.

A cunho interacionista pode ser observado no reconhecimento de que os sujeitos em interação formam uma rede que se transforma na e pela interação e no diálogo dos sujeitos entre si e com o mundo, a partir das trocas constantes que realizam ${ }^{(12)}$. A concepção interacionista pode ser observada também na rede de relações que se estabeleceu no grupo de professores quando da construção da Nova Graduação.

O aspecto sócio-cultural constitui-se no sentido de que o sujeito se constrói na relação com o mundo físico e social e de que o conhecimento é produzido nessa relação pelo contato com a sua realidade e com os outros, incluindo-se aqui a dimensão dialógica, inerente à própria construção do pensamento. É também pelo diálogo consigo mesmo e com o mundo que o cerca que o sujeito compreende sua própria natureza e percebe-se como um ser histórico. O sentido dialógico da relação pedagógica na proposta é visto como uma possibilidade de interação em que, ao 'convidar' e 'encontrar' o outro e seu mundo, os envolvidos possam a se atualizar no mundo(13), já que a educação, num sentido dialógico, leva educador e educando a construir, em conjunto, o mundo, num processo de reconhecimento e de (re)criação, mutuamente, a cada interação.

O indivíduo é indivíduo à medida em que é social, e o social, por sua vez, surge à medida que seus componentes são indivíduos. Essa relação, quando centrada em um dos pólos, anula no outro o exercício da autonomia. Quando centrada na possível interação entre os dois pólos potencializa a autonomia e requer sensibilidade para perceber outro. Para conviver cooperativamente, é preciso que cada um se reconheça em si mesmo na relação com o outro ${ }^{(16)}$.

A concepção epistemológica do curso pode ser considerada construtivista porque o conhecimento é entendido como um processo permanente de construção, que se transforma na interação do sujeito com o mundo a partir da ação do sujeito sobre o objeto de conhecimento e, conseqüentemente, das trocas que realiza.

A proposta pode ser considerada sistêmica porque o processo de conhecimento é compreendido como sendo um todo integrado cujas propriedades fundamentais têm sua origem nas relações entre suas partes. Constituído de sub-sistemas que se inter-relacionam formando uma rede, estão interligados e são interdependentes ${ }^{(15)}$. A partir de Maturana ${ }^{(16)}$, pode-se ver essa rede de aprendizagem como espaços de convivência para os quais se convida o outro, de modo que, estando o outro disposto a conviver conosco, possamos fluir no conviver. transformando-nos mutuamente.

O caráter transcendental emerge da compreensão do homem como parte integrante do universo, como um "ser" interdependente e inseparáveis de um Todo, numa caminhada individual de vir-a-ser apoiada na convivência , na compreensão, na cooperação e no respeito mútuos, contribuindo para a construção de um mundo mais justo, solidário e humano.

A cooperação define-se como um processo em ação; segundo Piaget ${ }^{(17)}$, cooperar na ação é operar em comum. Para que a cooperação se efetive deve-se observar que estejam presentes aspectos que a caracterizem, ou seja, a coordenação de pontos de vista diferentes, a presença de operações de correspondência, reciprocidade ou complementaridade, assim como a existência de regras autônomas de condutas fundamentadas de respeito mútuo. O autor também destaca que a existência de uma escala comum de valores e sua conservação, assim como a existência de uma reciprocidade de pensamento, são condições que devem ser necessariamente construídas por sujeitos em cooperação. Isto porque a consciência centrada apenas na autoridade do outro impede a cooperação, uma vez que a falta de consciência do eu não permite que esse se reconheça em relação às outras pessoas tornando-se inviável a ação do sujeito que apenas se submete às regras e as realiza em função do outro. Tanto a elaboração das regras, quanto a sua aplicação, devem ser fruto de um acordo mútuo devendo haver reciprocidade na sua execução. Caso contrário, sendo mantida a consciência centrada no outro, estará anulada a ação do indivíduo como sujeito. Para Piaget ${ }^{(18)}$, ser autônomo significa estar apto a construir cooperativamente o sistema de regras morais e operatórias necessárias à manutenção de relações permeadas pelo respeito mútuo.

A concepção epistemológica que apresentamos, resumidamente, está intimamente relacionada aos ideais explicitados na Pedagogia Inaciana. A Pedagogia Inaciana, que tem sua gênese na experiência espiritual de Inácio de Loyola, constitui-se numa proposta educativa que propõe uma mediação na qual a verdade, o conhecimento, a convivência, a solidariedade, a excelência humana e acadêmica são as metas a serem alcançadas ${ }^{(19)}$. Frente a esses preceitos, o conhecimento é visto como um processo que se constrói na 
interação dos sujeitos entre si e destes com o mundo, assim como na construção da autonomia para "ser", pensar e agir, ou seja, a Pedagogia Inaciana tem como princípio fundamental a formação integral da pessoa.

O princípio da transdisciplinaridade também foi um dos pilares sobre os quais se construiu a Nova Graduação da Unisinos, vindo a sustentar uma proposta de desenvolvimento em que se associam o ensino, a pesquisa e a extensão. Trazse a compreensão desse princípio como um modo de ver a construção do conhecimento que transcende as fronteiras disciplinares, baseia-se na crença de que as ciências, isoladamente, já não respondem adequadamente à nova exigência de flexibilidade e complementaridade dos saberes. Embora leve em conta que os saberes se originam das diferentes disciplinas implicadas, a transdisciplinaridade efetiva-se no movimento da ação cooperativa entre as mesmas, no estudo de um objeto comum. Constitui-se em um movimento que rompe com as fronteiras existentes entre as diferentes ciências, convidando ao deslocamento para um espaço de diálogo entre os diferentes saberes e ao trabalho coletivo.

\section{A Estrutura Curricular, a Proposta Metodológica e de Avaliação da Nova Graduação}

Só mudando nossa forma de pensar é que podemos modificar políticas e práticas profundamente enraizadas. Só mudando nossa forma de interagir poderemos estabelecer visões e compreensões compartilhadas, e novas capacidades de ação coordenada [...] A aprendizagem que altera os modelos mentais é altamente desafiadora, desorientadora. Pode ser assustadora ao confrontarmos crenças e pressupostos consagrados, não pode ser feita isoladamente. Só ocorre dentro de uma comunidade de aprendizes ${ }^{(20: 23))}$.

O Currículo na Nova Graduação é compreendido como uma rede conversacional de conhecimento, de convivência e de vida onde seus pontos de ligação se constroem no decorrer do processo de aprendizagem. Essas redes de conhecimento, na proposta do curso, são constituídas por Programas de Aprendizagem, que visam articular diferentes áreas de conhecimento e experiências de vida acadêmica e pessoal dos envolvidos no processo.

As metodologias desenvolvidas nos Programas de Aprendizagem devem considerar o respeito ao ritmo da aprendizagem e do desenvolvimento de cada sujeito, buscar favorecer a interdisciplinaridade, a aprendizagem cooperativa e a promoção da autonomia intelectual. Devem ainda incentivar a interatividade, as atividades investigativas e de criação, estimular a pergunta e a curiosidade científica.

A avaliação da aprendizagem no conjunto da Nova Graduação é entendida como um processo formativo e permanente de reconhecimento de saberes, competências, habilidades e atitudes, devendo ter, nas modalidades e nos critérios utilizados na sua realização, a correspondência com as concepções epistemológicas, princípios e pressupostos teóricos que sustentaram a sua elaboração. Seu objetivo, no contexto do curso, é, então, possibilitar o diagnóstico e o acompanhamento da aprendizagem, possibilitar a reorientação e a superação de dificuldades observadas, além de instigar o desenvolvimento pessoal e ajustes na prática docente.

A metodologia para a avaliação da aprendizagem deverá considerar, como ponto de partida, a criação e o estabelecimento coletivo dos critérios a serem considerados para a sua efetivação de modo que sejam conhecidos e assumidos por todos os envolvidos. Ao contrário do que tradicionalmente acontece, quando a integralização da avaliação é convertida em notas, as observações referentes ao processo de cada aluno em relação às atividades nos Programas de Aprendizagem são expressas, por cada professor ou grupo de professores do curso, em pareceres individuais da aprendizagem onde são manifestadas as considerações sobre o processo de cada aluno e onde é feito, sempre que necessário, o encaminhamento de ações pedagógicas que venham a auxiliar no avanço da aprendizagem.

\section{Organização do Curso e Programas de Aprendizagem}

Além de estar fundamentada nos princípios da Pedagogia Inaciana a estrutura e organização da proposta de formação é pensada e constituída a partir da idéia de inovação e da definição do perfil de um profissional capaz de acompanhar o seu tempo, com suficiente equilíbrio para não temer novos rumos e situações, em qualquer idade $^{(21: 12))}$.

A estruturação do curso a ser desenvolvido em Programas de Aprendizagem envolve uma base de organização curricular que substitui o sistema de disciplinas semestrais e justapostas de forma fragmentada na grade curricular, articulando os conteúdos a partir das áreas de conhecimento que se relacionam e da base disciplinar ${ }^{(22)}$.

A Nova Graduação da Unisinos é seriada e organizada em Programas de Aprendizagem que se inter-relacionam durante toda a formação profissional, sendo entendidos como espaços onde as diferentes áreas do conhecimento se articulam a partir das metodologias utilizadas. Cada Programa de Aprendizagem tem sua duração determinada pelas especificidades e pela natureza dos objetivos que o constituem.

Por ser seriado, o curso rompe com a lógica da formação em semestres e créditos e os alunos passam a conviver com o mesmo grupo de colegas ao longo do curso, socializando os saberes e as experiências que constituem o processo formativo.

A proposta didático-pedagógica e o processo de conhecimento desenvolvido em rede expressam a necessidade de uma organização que não esteja alicerçada sobre a determinação de um currículo fixo, mas que traga a contribuição de diferentes áreas do conhecimento, múltiplos saberes e habilidades cognoscitivos, sócio-culturais e emocionais, ultrapassando a lógica da racionalidade cognitivo-instrumental, levando em conta as diferenças, na sua pluralidade e heterogeneidade ${ }^{(23)}$.

A figura do espiral que vemos, pretende dar a idéia do movimento cognitivo ascendente que se espera possa se vivido por cada sujeito da aprendizagem. Pretende também representar a continuidade, o crescimento e a complexidade que se objetiva no desenvolvimento do curso em cada uma das suas atividades e, portanto, em cada um dos seus Programas de Aprendizagem.

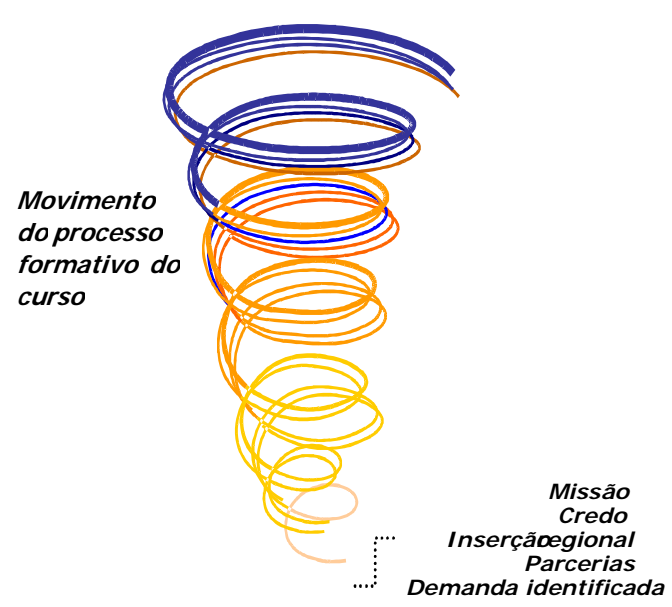

Cada Programa de Aprendizagem é constituído a partir da consideração dos conhecimentos específicos de cada profissão, dos problemas da realidade, das habilidades e das competências necessárias ao perfil do egresso. Essa conjectura é proposta pela equipe proponente do curso, que deve observar 
a formação do profissional em questão. Entretanto, os Programas de Aprendizagem devem ter a flexibilidade necessária de modo que possam ser ajustados no seu decorrer, considerando as particularidades da turma, as circunstâncias que conduzem à aprendizagem e o surgimento de novos conhecimentos. Deve, ainda, levar em conta, além da metodologia condizente com a concepção epistemológica e com os princípios que subsidiam a Nova Graduação, o aspecto ascensional e de complexidade do conhecimento que deve ser objetivo de cada programa de Aprendizagem e, conseqüentemente, do curso como um todo.

\section{Conclusões provisórias...}

Ao resumirmos essa experiência apresentamos o novo formato construído para a graduação na Unisinos. Relembramos que o processo foi assim desenvolvido porque a equipe que o projetou acreditou e acredita, que educação não se faz com passividade, por osmose ou ventriloquia teórica, mas por meio de alternativas pedagógicas que se atualizem no tempo e que estimulem a aprendizagem. Reafirmamos que entendemos o aprender como um exercício de (re)criação complexo, permeado pela incompletude, pela dificuldade, pela vontade, pela ousadia e pelo prazer do crescimento pessoal.

O modelo da Nova Graduação já está acontecendo na Universidade desde fevereiro. A experiência da sua operacionalização vem favorecendo uma vivência acadêmica interna inédita. Inclui, entre outras coisas, o planejamento semanal coletivo das atividades dos Programas de Aprendizagem, uma avaliação processual compartilhada e a construção "na ação". O desafio da construção de um currículo em rede, sempre atual, pautado pelo rigor e integrado às necessidades regionais, implica desafios e ajustes intensos e constantes e uma cooperação ímpar. Longe ficou a possibilidade do refúgio do comodismo e da mesmice. Todos somos impelidos diuturnamente à procura de alternativas que contemplem a consecução da proposta e ao encontro com os demais para dar conta de um processo que vai se construindo à medida que os desafios se impõem e a vontade dos sujeitos incita ao novo e ao inusitado.

Encerramos a conversa esperando um retorno, curiosas em relação à repercussão que essa comunicação suscitou e dispostas a ouvir as diferentes críticas que se fizerem necessárias, para que possamos avançar no nosso processo de formação. Temos certeza de que, tanto quanto mexeu conosco a experiência de realizar e partilhar esse processo, indubitavelmente ela provocará reações diversas e imprevisíveis. Porém, é imprescindível que o diálogo continue e se institua entre pessoas que se envolvem no compromisso de exercer a profissão do ensinar e que pretendem que a aprendizagem aconteça nas trocas que nos permitimos.

\section{Referências}

1. Vasconcellos MJE. Pensamento sistêmico: o novo paradigma da ciência. São Paulo: Papirus; 2003.

2. Larrosa JB. Notas sobre a experiência e o saber de experiência. Revista Brasileira de Educação, 2002 jan/abr;(25).

3. Larrosa JB. Literatura, experiência e formação. In: Costa MV, organizadora. Caminhos investigativos: novos olhares na pesquisa em educação. $2^{\mathrm{a}}$ ed. Rio de Janeiro: DP\& A; 2002. p.133-61.

4. UNISINOS. Princípios e pressupostos norteadores para a construção de uma nova graduação de referência. São Leopoldo (RS): UNISINOS; 2002.

5. UNISINOS. Planejamento estratégico. São Leopoldo (RS): UNISINOS; 2002.

6. Maturana HR, Varela FG. A árvore do conhecimento: as bases biológicas do entendimento humano. São Paulo: editora; 1995. Total de páginas.

7. Cunha MI. O professor universitário na transição de paradigmas. Araraquara (SP): JM; 1998.

8. Universidade de São Paulo, Curso de Humanidades. PUCPR: Projeto Pedagógico da Reformulação Curricular. São Paulo: 2002. (texto digitado).

9. UNISINOS. Princípios e pressupostos norteadores para a construção de uma nova graduação de referência. São Leopoldo (RS): UNISINOS; 2002.

10. Daudt SID. Acoplamento tecnológico e desenvolvimento de um novo domínio consensual no operar do ensino, pesquisa e extensão [projeto de tese apresentado ao Programa de Pós-Graduação em Informática na Educação da Universidade Federal do Rio Grande do Sul]. Porto Alegre (RS); 2003.

11. Catapan AH, Fialho FA. Autonomia e sensibilidade na rede: uma proposta. In: $6^{\circ}$ Congresso Internacional de Educação a Distância. Disponível em: URL: <http://www.abed.org.br/antiga/htdocs/ paper_visem/araci hack catapan.htm>. Acessado em: 22 maio 2003.

12. Princípios e pressupostos norteadores para a construção de uma nova graduação de referência. São Leopoldo (RS): UNISINOS; 2002.

13. Maturana HR. Uma nova concepção de aprendizagem: palestra na Universidade católica de Santiago do Chile. [transcrição de Nelson Vaz e Cristina Magro]. Revista dos Pontos, Santiago, 1993 outono/ inverno;2(15):28-32.

14. Piaget J. Estudos sociológicos. Rio de Janeiro: Forense; 1973.

15. Senge PM. A quinta disciplina: arte e prática da organização que aprende. São Paulo: Best Seller; 2000.

Data de recebimento: 31/08/2003

Data de aprovação: 30/10/2003 